\title{
Présentation de l'entretien
}

\section{Anne-Yvonne Julien}

\section{(2) OpenEdition}

\section{Journals}

Édition électronique

URL : http://journals.openedition.org/ccs/928

DOI : $10.4000 /$ ccs. 928

ISSN : 2558-782X

\section{Éditeur :}

Presses universitaires de Rennes, Association des lecteurs de Claude Simon

\section{Édition imprimée}

Date de publication : 31 mai 2014

Pagination : 21-23

ISBN : 9782753533387

ISSN : 1774-9425

\section{Référence électronique}

Anne-Yvonne Julien, « Présentation de l'entretien », Cahiers Claude Simon [En ligne], 9 | 2014, mis en ligne le 22 septembre 2017, consulté le 24 septembre 2020. URL : http://journals.openedition.org/ccs/ 928 ; DOI : https://doi.org/10.4000/ccs.928 
Cet entretien, rappelons-le, figure dans le numéro consacré à Claude Simon de la revue Entretiens des éditions Subervie ${ }^{1}$, fondée par un petit noyau d'enthousiastes de la littérature et de la poésie contemporaines dont le poète Frédéric-Jacques Temple: il voisine avec une republication des "Cinq notes sur Claude Simon de Maurice Merleau-Ponty", des paroles de traducteurs ou de critiques étrangers (T. Bishop, J. Fletcher, C. G. Bjurström ou R. Howard), des points de vue novateurs d'essayistes ou de théoriciens de la littérature (Raymond Jean, Jean Ricardou, Serge Doubrovsky) et accueille également le texte bref encore intitulé Femmes, sur vingt-trois peintures de Joan Miró, qui deviendra La Chevelure de Bérénice ${ }^{2}$.

Il s'agit là d'un épitexte qui mérite d'être examiné avec attention. Les conditions dans lesquelles il a été réalisé font que le romancier a pris le temps de développer sa réflexion jusque dans ses ramifications les plus fines. On le sent en confiance face à un interlocuteur à l'écoute, particulièrement aigu dans sa progression. Rappelons que Ludovic janvier (né en 1934) est tout à la fois critique et écrivain, qu'au moment de l'échange, il est connu pour s'être attaché à expliciter les options esthétiques du Nouveau Roman et qu'il est l'auteur de deux livres essentiels sur Beckett, parus au Seuil ${ }^{3}$.

Cet échange s'oriente très vite vers un bilan de trente années de production textuelle. Simon vient de faire paraître Les Corps conducteurs (1971) qui est un peu l'acmé de sa période expérimentale. Nous avons donc la chance, en quelque sorte, de relire cet état des lieux d'une œuvre au début de la décennie 70, avec la connaissance que nous avons de l'œuvre ultérieure. Il est d'ailleurs stimulant de constater que le romancier s'installe d'emblée dans le relativisme d'une évaluation rétrospective, saisissant ici encore l'occasion de rappeler qu'il ne peut plus coïncider avec celui qui a publié cinq, dix ou vingt ans plus tôt.

1. Les autres membres fondateurs sont Denys-Paul Bouloc, qui fut l'ami d'Artaud lorsque celui-ci séjourna à l'asile de Rodez, Jean Digot co-fondateur avec Frédéric-Jacques Temple des « Journées de poésie » (à partir de 1951) et Pierre Loubière, poète-paysagiste, auteur entre autres recueils de Mémoire buissonnière (1976).

2. La première édition du texte, à tirage limité (sous le titre Femmes) est celle des éditions Maeght (1966), illustrée de reproductions de peintures de Joan Miro. Le texte est reparu sans illustrations en 1984 aux éditions de Minuit: il figure dans le premier volume des Euvres de Claude Simon dans la « Bibliothèque de la Pléiade ", dir. A. Duncan, avec la collaboration de J. Duffy, 2006.

3. Pour Samuel Beckett, Minuit, 1966, et Samuel Beckett par lui-même, Le Seuil, 1969. 
Dans cet ensemble de réponses, il est loisible de repérer un certain nombre d'affirmations que nous retrouverons différemment modulées dans les autres textes " théoriques" de l'auteur, souvent plus tardifs, entretiens divers, conférences données ici ou là pour une circonstance précise, essais importants comme la "Préface à "Orion aveugle" " (1970), "La Fiction mot à mot " (1972), ou le Discours de Stockholm (1986).

Quelles seraient ces grandes lignes récurrentes?

D'abord, une défiance toujours exprimée par rapport à une littérature de représentation, la promotion en contraste d'une littérature de recherche dans la lignée proustienne, le refus d'une causalité socio-psychologique soustendant une intrigue romanesque, l'allergie à un dénouement du récit présenté comme le " couronnement logique " d'un itinéraire de personnage, et le rappel également que cette défiance vaut d'être reformulée dans la mesure où la critique journalistique n'est malheureusement pas sortie d'un tel schéma, oubliant souvent que le chemin d'une création renouvelée a été indiqué par les œuvres de "Kafka, Joyce et Proust».

Ensuite, une redéfinition de la notion de « continuité » en contexte narratif. Manière pour Simon de souligner que le roman tel qu’il le conçoit, n’en déplaise à la critique académique, ne va pas dans tous les sens, qu'il substitue simplement à une linéarité factice, fondée sur une succession arbitraire d'épisodes fictifs, une continuité d'écriture née d'associations qualitatives entre divers éléments du récit. "Continuité » dont la peinture la plus audacieuse est également illustrative lorsqu'elle se soumet à des impératifs rigoureusement picturaux.

Enfin, une mise au point sur le sens de l'expression " ne pouvoir rien inventer » qui lui est rappelé par Ludovic Janvier comme étant sienne et qui, selon son dire, n'équivaut ni à un brevet de réalisme ni à une velléité de témoignage. Certes, le romancier concède que des situations éprouvées à Barcelone en 1936 ou pendant la guerre ont été déterminantes dans son parcours d'existence et qu'on ne peut écrire qu'à partir d'une expérience sensible mais il prend soin d'énumérer toutes les médiations déformantes par lesquelles passe " un événement réel " pour devenir "un événement écrit ", imputables aux approximations de la perception, à une mémoire plus ou moins faillible, au projet du scripteur, à l'élaboration d'une poétique ou même au respect des contraintes productrices de la langue.

Mériteraient d'être également soulignés deux points plus spécifiques à cet entretien.

Il y aurait, par exemple, le regard que Simon porte sur les débuts de son itinéraire de romancier: à Janvier qui dessine une première période s'étendant du Tricheur (1945) au Sacre du printemps (1954), et décerne au Vent (1957) le statut de texte fondateur, Simon répond en plaçant la barre de scansion avant L'Herbe 
(1958), préférant deviner dans ce qui précède, mis à part le faux-pas de Gulliver, " une lente évolution par tâtonnements ", et datant de la rédaction d'Histoire (1967), la prise de conscience d'une nouvelle voie essayée avec L'Herbe, le choix de s'abandonner en conscience "à ce que l'écriture découvr[e] ". Il accorde également à son interviewer que $\mathrm{La}$ Corde raide annonce bien $\mathrm{La}$ Route des Flandres (1960), Le Palace (1962) et Histoire mais "à la façon d'un répertoire, d'un inventaire de thèmes » et il a des mots un peu durs pour stigmatiser "le ton d'assurance et de provocation " de ce récit de jeunesse en lequel il décèle une forme d'immaturité.

Autre moment important de l'entretien, celui où Ludovic Janvier, que l'on sait également grand lecteur de Beckett, tente de conduire Claude Simon du côté d'une interrogation sur la possible fascination de la mort qui traverserait son œuvre. Simon ne se laisse assurément pas enfermer dans une question qui relève pour lui de la psychologie ou de la métaphysique. Néanmoins, il reconnaît que " le pourrissement, l'érotisme, la nostalgie du corps » sont effectivement des thèmes qui lui sont familiers. Et il entend ce que Janvier suggère en lui citant l'épigraphe d'Histoire, à savoir que ses textes pourraient être lus comme un combat contre le tragique de l'Histoire. Mais il refuse énergiquement le principe d'une tentative de salut par l'art. Tout au plus, accepte-t-il l'idée que son œuvre "prenne place dans l'histoire "; et elle ne le pourra, estime-t-il, que «dans la mesure où elle aura apporté des formes neuves participant de et à l'incessante transformation du monde ». Pas de position de surplomb donc mais une confiance réaffirmée dans le travail qui s’accomplit à travers la durée. "Vous savez bien $[. .$.$] qu'écrire, c'est une sorte de travail de taupe »...$ 